\title{
Autoamputation of the ovary: a rare consequence of torsion in a mature cystic teratoma
}

\author{
Nitin H. Shah', Aditi V. Joshi1*, Amit Pilankar², Shweta Pilankar ${ }^{2}$
}

\begin{abstract}
${ }^{1}$ Department of Obstetrics and Gynaecology, Vardann Multispeciality Hospital, Kandivali, Mumbai, Maharashtra, India

${ }^{2}$ Department of Obstetrics and Gynaecology, Siddhi Maternity Nursing Home, Mumbai, Maharashtra, India
\end{abstract}

Received: 02 September 2019

Accepted: 01 October 2019

\section{*Correspondence:}

Dr. Aditi V. Joshi,

E-mail: avj111@gmail.com

Copyright: (c) the author(s), publisher and licensee Medip Academy. This is an open-access article distributed under the terms of the Creative Commons Attribution Non-Commercial License, which permits unrestricted non-commercial use, distribution, and reproduction in any medium, provided the original work is properly cited.

\begin{abstract}
Autoamputation of the ovary may be a result of longstanding infarction resulting from torsion of the ovarian pedicle. This entity may be confused with an ectopic or supernumerary ovary. A proper detailed history taking is important to provide clues for diagnosis. We report a case of a young female patient diagnosed with autoamputation of unilateral ovary on laparoscopy, with histopathology confirmation of ovary with dermoid cyst.
\end{abstract}

Keywords: Autoamputation of ovary, Dermoid cyst, Laparoscopy, Rare phenomenon, Torsion, Young patients

\section{INTRODUCTION}

Autoamputation of the ovary is a rare clinical phenomenon with an undetermined aetiology. ${ }^{1}$ Mature cystic teratoma is a common benign ovarian mass encountered in the reproductive age group and has a high propensity for undergoing torsion. The sensitivity and specificity of diagnosing torsion ovary by ultrasonography, especially with colour doppler is operator dependent. ${ }^{2}$ However, multiple studies have shown that this modality of imaging is an effective tool for diagnosis. ${ }^{3,4}$ The diagnosis of this condition remains challenging in patients with obscure clinical presentation.

\section{CASE REPORT}

26-year-old, nulligravida married since 2 years, not anxious to conceive came to the out-patient department with complaints of intermittent pain in abdomen since 1 year. She had a bout of severe pain almost a year back, however no investigations were done for the same and the pain was relieved with medications. There were no other associated complaints. Her past medical history was insignificant. On examination vital parameters were normal. Cardiovascular and respiratory system examination was within normal limit. On per abdomen examination, abdomen was soft with mild tenderness in right iliac fossa. On per vaginal examination uterus was normal size, anteverted, bilateral fornices free.

Ultrasonography revealed a complex cyst in the right adnexa, approximately $4 X 5 \mathrm{~cm}$ more on anterior aspect of the uterus with mixed echogenicity suggestive of a dermoid cyst. Routine blood investigations and hormonal profile was normal. Patient was counselled and laparoscopy was planned for the evaluation and excision of the ovarian mass. On laparoscopy, the right ovary was not seen at the anatomical location and seemed to be lying in the vesico-uterine pouch (Figure 1). The right fallopian tube also seemed partly atretic, probably owing to previous torsion which could explain an autoamputation of the ovary on that side. The ovary appeared to be enlarged, bulky hardened with a thick capsule. The left ovary seemed to have a hemorrhagic cyst around $2 \mathrm{~cm}$ but otherwise was normal so also was 
the left fallopian tube (Figure 2). The auto-amputated ovary was then removed via laparoscopy using a retrieval bag (Figure 3) and sent for histopathological examination, which was suggestive of a dermoid cyst with viable ovarian tissue. The uterus appeared to be normal in shape and size (Figure 4).

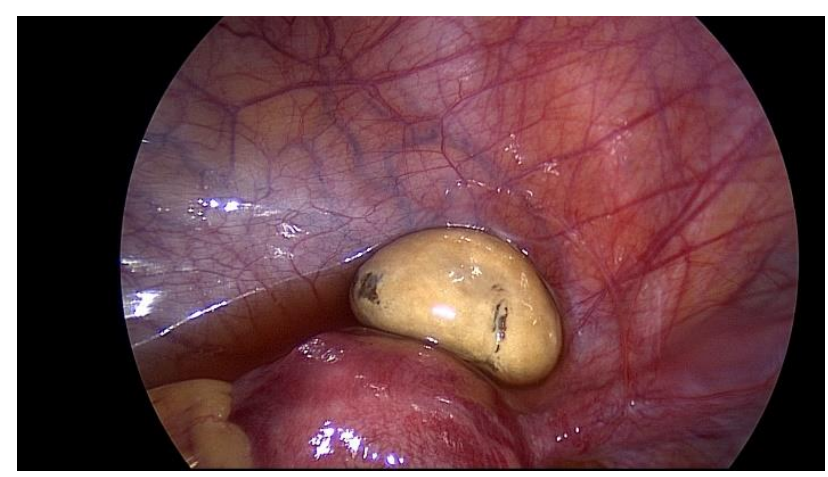

Figure 1: Illustrating the ectopic location of the ovary in the vesico-uterine pouch.

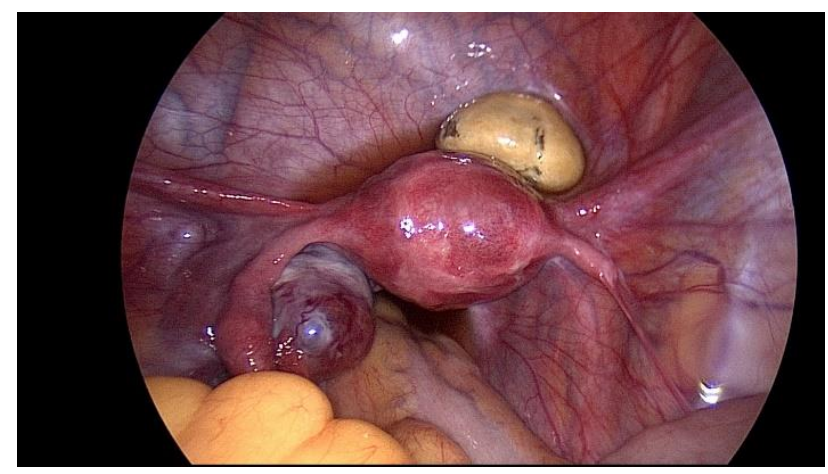

Figure 2: Illustrating the auto-amputated of right ovary, with abrupt end of the right fallopian tube. Presence of normal anatomical location of the left tube and ovary with a hemorrhagic cyst in the left ovary.

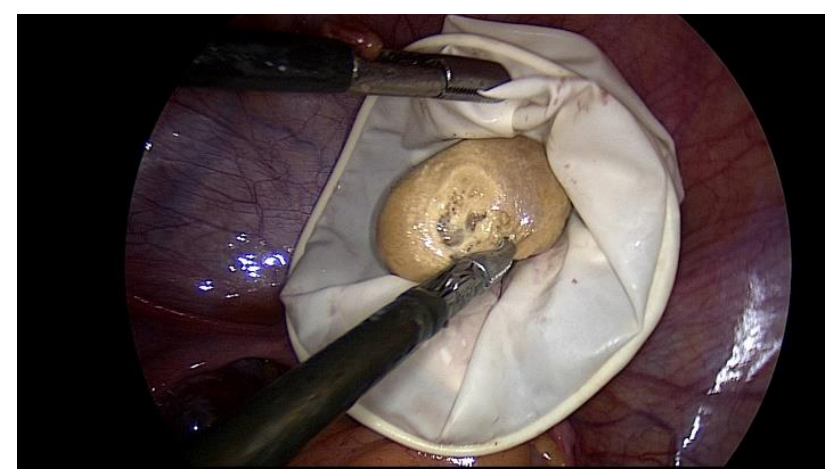

Figure 3: Depicts the removal of the auto-amputated ovary via a glove retrieval bag.

Post-operative course of the patient was uneventful. She was discharged on the second day post procedure. She conceived spontaneously after 6 months and is currently in her $12^{\text {th }}$ week of gestation.

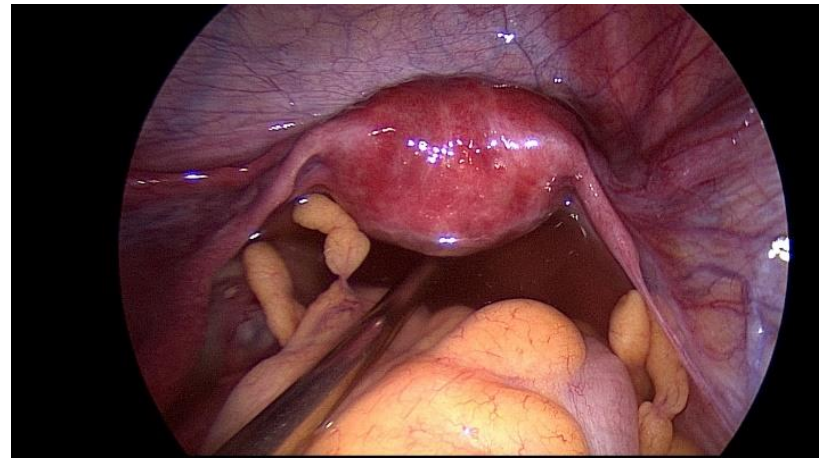

Figure 4: The final view depicting a normal shape of the uterus.

\section{DISCUSSION}

Dermoid cyst, a subtype of germ cell tumours are the commonest occurring benign ovarian neoplasm accounting for $25 \%$ of all benign ovarian masses. ${ }^{5}$ Torsion is the most common complication of a dermoid cyst and adnexal torsion is seen in almost $3.5 \%$ cases of mature cystic teratoma. ${ }^{6}$ Parasitic dermoid cysts are rare. They are known to occur due to development of dermoid cyst in a supernumerary ovary, primary dermoid developing in a displaced germ cell or autoamputation. ${ }^{7}$

The pathogenesis of autoamputation is complex. In acute cases, it is believed that tissue infarction can lead to necrosis and atrophy and thus subsequently cause amputation. In subacute or chronic conditions, it has been noted that the teratoma develops a collateral circulation of its own and gets detached from the pedicle over a period of time, forming a parasitic dermoid. ${ }^{8}$ There have been reports of re-implantation of these parasitic dermoids, especially in the omentum.

An alternate theory suggested the development of dermoid in ectopic ovary. This may arise in congenital ectopic ovary, which is difficult to ascertain in most cases. Also, the theory which suggests development of dermoid in displaced primordial germ cells does not seem plausible in our case, since histopathology showed presence of viable ovarian tissue. Owing to the nonspecific clinical presentation, diagnosis of chronic cases often becomes challenging. Ultrasonography is the best imaging modality available for the detection of torsion and the addition of colour Doppler increases the sensitivity and specificity of diagnosis. ${ }^{3,9}$

Evidence suggests a laparoscopic approach is better than laparotomy for such cases. The teratoma must be retrieved via a tissue retrieval bag to avoid inadvertent spill into the peritoneal cavity.,10 The presence of previous symptoms and the histopathological findings suggestive of viable ovarian tissue in the dermoid, indicate that the present case was most probably due to autoamputation. Lipoleiomyoma is a rare differential postulated which may mimic an ovarian dermoid, it comprises of a mass of lipid collection. ${ }^{11}$ 


\section{CONCLUSION}

Ovarian autoamputation is a rare and challenging condition to diagnose. Every clinician must be aware of this entity and early symptoms of abdominal pain must not be ignored. This measure could help avoid this sequela in cases which arise as a consequence to chronic torsion.

Funding: No funding sources Conflict of interest: None declared

Ethical approval: Not required

\section{REFERENCES}

1. Peitsidou A, Peitsidis P, Goumalatsos N, Papaspyrou R, Mitropoulou G, Georgoulias N. Diagnosis of an autoamputated ovary with dermoid cyst during a Caesarean section. Fertil Steril. 2009;91:1294.e9-12.

2. Sasaki KJ, Miller CE. Adnexal torsion: review of the literature. J Minim Invasive Gynecol. 2014;21:196202.

3. Nizar K, Deutsch M, Filmer S, Weizman B, Beloosesky R, Weiner Z. Doppler studies of the ovarian venous blood flow in the diagnosis of adnexal torsion. J Clin Ultrasound. 2009;37:436-9.

4. Valsky DV, Esh-Broder E, Cohen SM, Lipschuetz M, Yagel S. Added value of the gray-scale whirlpool sign in the diagnosis of adnexal torsion. Ultrasound Obstet Gynecol. 2010;36:630-4.
5. Medeiros LR, Rosa DD, Bozzetti MC, Fachel JM, Furness S, Garry R, et al. Laparoscopy versus laparotomy for benign ovarian tumour. Cochrane Database Syst Rev. 2009:CD004751.

6. Oelsner G, Shashar D. Adnexal torsion. Clin Obstet Gynecol. 2006;49:459-63

7. Kusaka M, Mikuni M. Ectopic ovary: A case of autoamputated ovary with mature cystic teratoma into the cul-de-sac. J Obstet Gynaecol Res. 2007;33:368-70.

8. Khoo CK, Chua I, Siow A, Chern B. Parasitic dermoid cyst of the pouch of Douglas: a case report. J Minim Invasive Gynecol. 2008;15:761-3.

9. Sinha R, Sundaram M, Lakhotia S. Multiple intraabdominal parasitic cystic teratomas. J Minim Invasive Gynecol. 2009;16:789-91.

10. Park JY, Kim DY, Suh DS, Kim JH, Nam JH. Laparoendoscopic single-site versus conventional laparoscopic surgery for ovarian mature cystic teratoma. Obstet Gynecol Sci. 2015;58:294-301.

11. Oh SR, Cho YJ, Han M, Bae JW, Park JW, Rha SH. Uterine lipoleiomyoma in peri or postmenopausal women. J Menopausal Med. 2015;21:165-70.

Cite this article as: Shah NH, Joshi AV, Pilankar A, Pilankar S. Autoamputation of the ovary: a rare consequence of torsion in a mature cystic teratoma. Int J Reprod Contracept Obstet Gynecol 2019;8:4564-6. 